\title{
Conversion of carboxylic acids to potassium acyltrifluoroborates (KATs) by Cu- catalyzed borylation of mixed anhydrides
}

Pinku Tung, ${ }^{[a] \#}$ Anne Schuhmacher, ${ }^{[b] \#}$ Philipp E. Schilling, ${ }^{[b]}$ Jeffrey W. Bode, ${ }^{[b] *}$ Neal P. Mankad[ ${ }^{[\mathrm{a} *}$

[a] Department of Chemistry, University of Illinois at Chicago, 845 W. Taylor St., Chicago, IL 60607 (USA)

E-mail:npm@uic.edu

[b] A. Schuhmacher, P. Schilling, Prof. J. W. Bode

Laboratory of Organic Chemistry, ETH Zurich, Vladimir-Prelog-Weg 3, 8093 Zurich (Switzerland)

E-mail: bode@org.chem.ethz.ch

\# These authors contributed equally to this work.

Abstract: We report the preparation of potassium acyltrifluoroborates (KATs) from widely-available carboxylic acids. Mixed anhydrides of carboxylic acids were prepared using isobutyl chloroformate and transformed to the corresponding KATs using a commercial copper catalyst, $\mathrm{B}_{2}(\mathrm{pin})_{2}$ and aqueous $\mathrm{KHF}_{2}$. This method allows for the facile preparation of aliphatic, aromatic, and amino acid-derived KATs and is compatible with a variety of functional groups including alkenes, esters, halides, nitriles, and protected amines.

Potassium acyltrifluoroborates (KATs) are stable acylboron species that participate in a variety of unique and valuable reactions. They undergo rapid amide-forming ligation with hydroxylamines ${ }^{1}$ or $N$-chloroamines ${ }^{2}$ and form stable zwitterionic trifluoroborate iminiums (TIMs) with amines. ${ }^{3}$ This has led to their application in protein conjugation, ${ }^{4}$ peptide and protein modification, ${ }^{2 \mathrm{~b}, 5}$ and for polymer and materials chemistry. ${ }^{6}$ Several approaches allow access to KATs from aryl halides, ${ }^{7}$ alkyl halides, ${ }^{8}$ Grignard reagents, ${ }^{9}$ aldehydes, ${ }^{10}$ aryl- and vinyl boronic acids, ${ }^{11}$ and alkynes. ${ }^{12}$ Although these methods enable the preparation of numerous KATs, they require several synthetic steps or are only applicable for a rather small scope of substrates. To date, there is but a single example of the preparation of acyltrifluoroborate from a carboxylic acid derivative, using a borylzinc reagent that is challenging to access (Figure 1a). ${ }^{13}$

As alternatives, the Ito group developed a two-step borylation/oxidation of aldehydes to approach KATs, including amino acid-derived KATs. ${ }^{10 \mathrm{~b}}$ The Mankad group's recent report of a copper-catalyzed carbonylative KAT synthesis from alkyl iodides (Figure 1b) that proceeds via the intermediacy of an acyl iodide implies that other activated carboxylic acid species could be suitable as starting materials for the preparation of KATs. ${ }^{8}$ Using 
this insight as a starting point, we have now developed conditions that allow for the preparation of KATs from acid anhydrides and show that this methodology can be applied for the synthesis of a variety of aromatic and aliphatic KATs, including amino acid-derived KATs (Figure 1c).

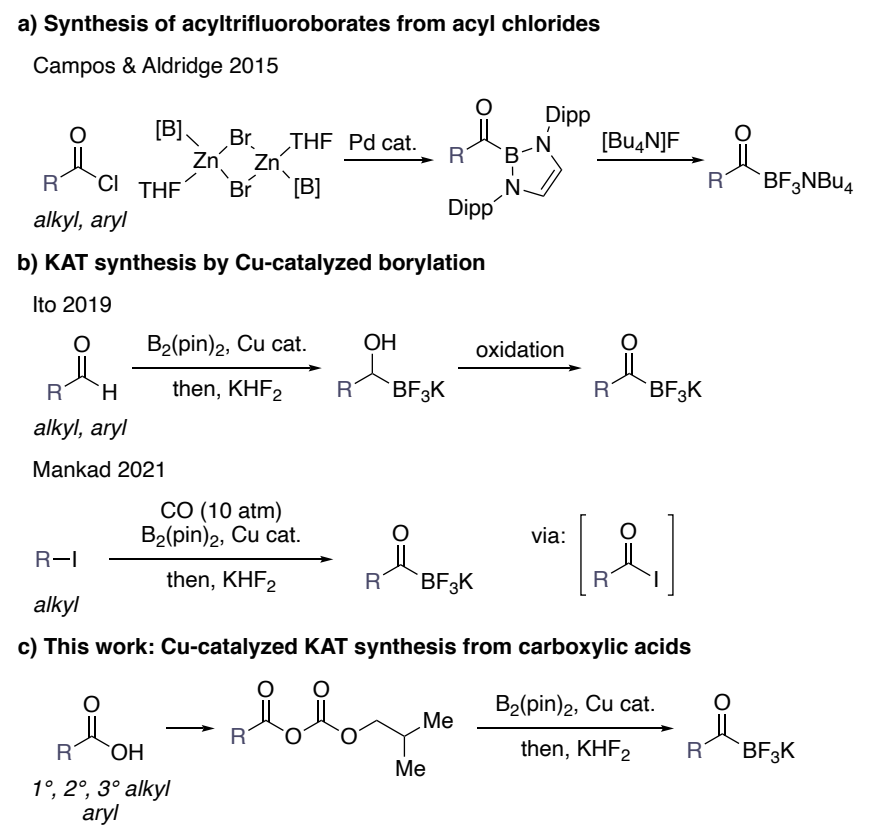

Figure 1. Preparation of acyltrifluoroborates from acyl chlorides and by coppercatalyzed methods. Dipp $=2,6$-diisopropylphenyl, pin $=$ pinacol.

As our previous study indicated that the KAT formation proceeds via an acyl iodide intermediate, we began our study with nonanoyl chloride owing to the higher availability of acyl chlorides than acyl iodides. ${ }^{8}$ From prior work, we recognized that alkoxide bases play a crucial role in generating catalytically active borylcopper species, and initially attempted borylation of nonanoyl chloride with $\mathrm{B}_{2}(\mathrm{pin})_{2}$ by screening different alkoxide bases. All attempts to obtain the desired KAT were unsuccessful, and we instead observed the formation of esters. The use of octanoic anhydride as our model substrate, however, provided a modest yield of the desired KAT, and we were pleased to find that a mixed anhydride of 4-phenylbutyric acid (1a) and isobutyl chloroformate also gave small amounts of the desired KAT (2a) using NaOMe and catalytic IPrCuCl (Table 1, entry 2).

We used this mixed anhydride to further optimize the reaction conditions. Other alkoxide bases (Table 1, entries $1-4$ ) led to $<5 \%$ yield, but screening of different $(\mathrm{NHC}) \mathrm{CuCl}$ catalysts (entries 5-7) revealed IMesCuCl as superior, providing $47 \%$ yield (entry 6 ). Variation in the reaction stoichiometry or temperature did not improve the yield (entries 8-11). However, when the reaction time was increased from $2 \mathrm{~h}$ to $4 \mathrm{~h}$, the yield improved 
to $72 \%$ (entry 12). Further elongation of the reaction time did not result in improvements (entry 13). In order to increase the yields particularly for more challenging substrates, we selected $15 \mathrm{~mol} \% \mathrm{IMesCuCl}, 1.0$ equiv $\mathrm{B}_{2}$ (pin)2, and 2.0 equiv $\mathrm{NaOMe}$, followed by quenching with $\mathrm{KHF}_{2}$ as standard conditions for the conversion of carboxylic acid derivatives to KATs.

Table 1. Selected optimization studies. ${ }^{[a]}$

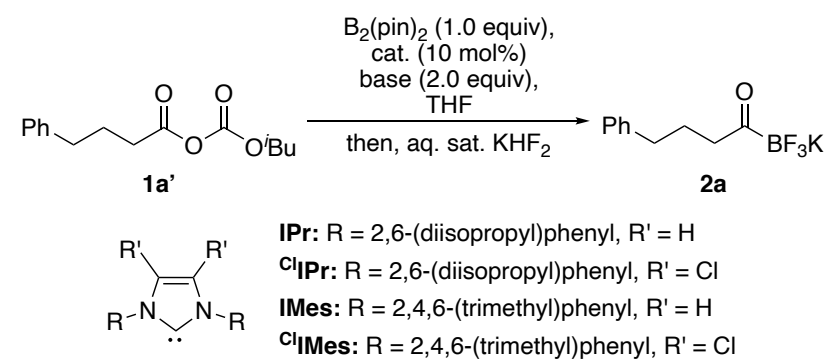

\begin{tabular}{lllll}
\hline Entry & Catalyst & Base & Time (h) & Yield (\%) \\
\hline 1 & IPrCuCl & LiOMe & 2 & $<5$ \\
2 & IPrCuCl & NaOMe & 2 & 16 \\
3 & IPrCuCl & LiOtBu $^{t}$ & 2 & $<5$ \\
4 & IPrCuCl & NaOtBu & 2 & $<5$ \\
5 & ClIPrCuCl & NaOMe & 2 & 36 \\
6 & IMesCuCl & NaOMe & 2 & 47 \\
7 & ClIMesCuCl & NaOMe & 2 & 33 \\
$8^{[b]}$ & IMesCuCl & NaOMe & 2 & 28 \\
$9^{[c]}$ & IMesCuCl & NaOMe & 2 & 23 \\
$10^{[d]}$ & IMesCuCl & NaOMe & 2 & 20 \\
$11^{[\mathrm{e}]}$ & IMesCuCl & NaOMe & 2 & 12 \\
12 & IMesCuCl & NaOMe & 4 & 72 \\
13 & IMesCuCl & NaOMe & 18 & 68 \\
\hline
\end{tabular}

[a] Experimental details are described in the supporting information. Reactions were performed on $0.1 \mathrm{mmol}$ scale. Yields were determined by ${ }^{19} \mathrm{~F}$ NMR using fluorobenzene as an internal standard. [b] 2.0 equiv $\mathrm{B}_{2} \mathrm{Pin}_{2}$. [c] 2.0 equiv anhydride. [d] 1.0 equiv NaOMe. [e] Performed at $0{ }^{\circ} \mathrm{C}$.

With these optimized conditions, we investigated the substrate scope of the reaction (Scheme 2). KATs derived from primary carboxylic acids (2a-2j) were obtained in good yields, including KATs bearing substituted phenyl rings $(\mathbf{2 b}-\mathbf{2 e})$ or a terminal alkene $(\mathbf{2 h})$. Importantly, this method could also be applied to secondary and tertiary alkyl acids, providing KATs that are difficult to obtain by other methods. Both cyclic (2I) and acyclic $(2 \mathrm{k})$ secondary products were obtained in good yield. The challenging tertiary substrates also yielded the corresponding KAT products $(\mathbf{2 m}, \mathbf{2 n})$, albeit with lower yields. We further 
demonstrated that this method could be expanded to prepare aromatic KATs in excellent yields (2o-2t). Aromatic KATs with electron-donating methoxy (2s) and electronwithdrawing nitrile (2t) groups, and a thiophene derivative (2r), were readily obtained. We additionally showed that the reaction can be performed on $10 \mathrm{mmol}$ scale in similar isolated yields for products $\mathbf{2 l}$ and $\mathbf{2 0}$. Some $\mathbf{N}$-containing heteroaromatic substrates, as well as alkenyl and alkynyl carboxylic acids could not be converted into the desired products $(\mathbf{2} \mathbf{u}-\mathbf{w})$ with this method.

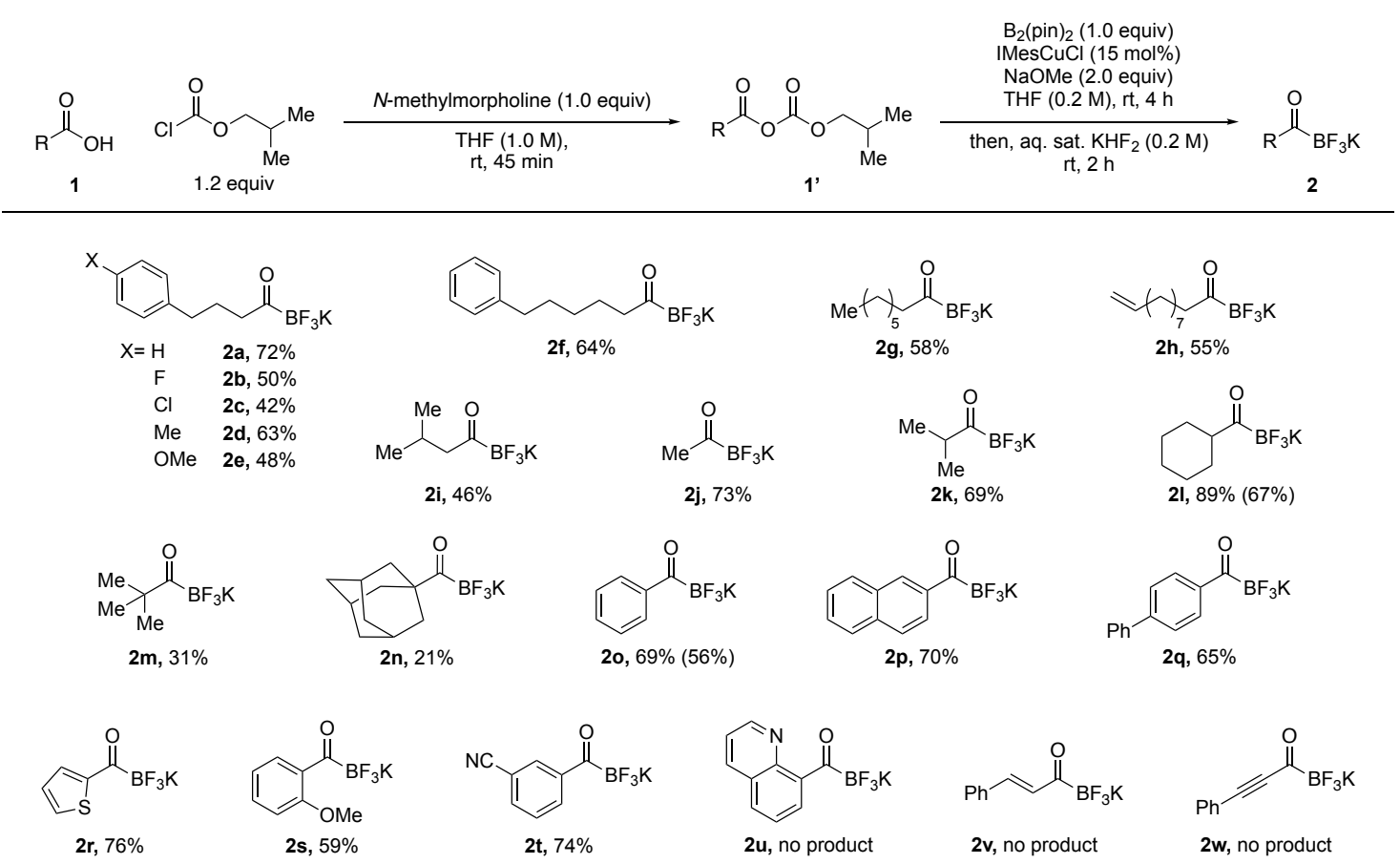

Scheme 1. Substrate scope for the preparation of KATs. Isolated yields are reported. Reactions were performed on $1 \mathrm{mmol}$ scale. Yields in parentheses are for the reaction performed on $10 \mathrm{mmol}$ scale. $\mathrm{B}_{2}$ (pin) $)_{2}=$ bis(pinacolato)diboron; $\mathrm{IMesCuCl}=\mathrm{Chloro}(1,3-$ dimesitylimidazol-2-ylidene)copper(I).

KATs derived from amino acids are of particular interest for applications in peptide synthesis and protein conjugation using KAT ligation. ${ }^{10 \mathrm{~b}, 12 \mathrm{a}, \mathrm{b}, 14}$ So far, these KATs are best prepared by the route described by Ito and coworkers in 2019 and involves preparation of the amino acid aldehyde, followed by a $\mathrm{Cu}(\mathrm{I})$-catalyzed borylation to give the $\alpha$-hydroxytrifluoroborate. Subsequent oxidation with nor-AZADO yields the amino acid KAT. ${ }^{10 \mathrm{~b}}$ The new route reported here allows for preparation of the KATs directly from Fmoc-, Boc-, or Cbz-protected amino acids (Scheme 2). The major challenge is purification of these KATs, as they show good solubility in $\mathrm{CH}_{2} \mathrm{Cl}_{2}$ and partial solubility in $\mathrm{Et}_{2} \mathrm{O}$. 


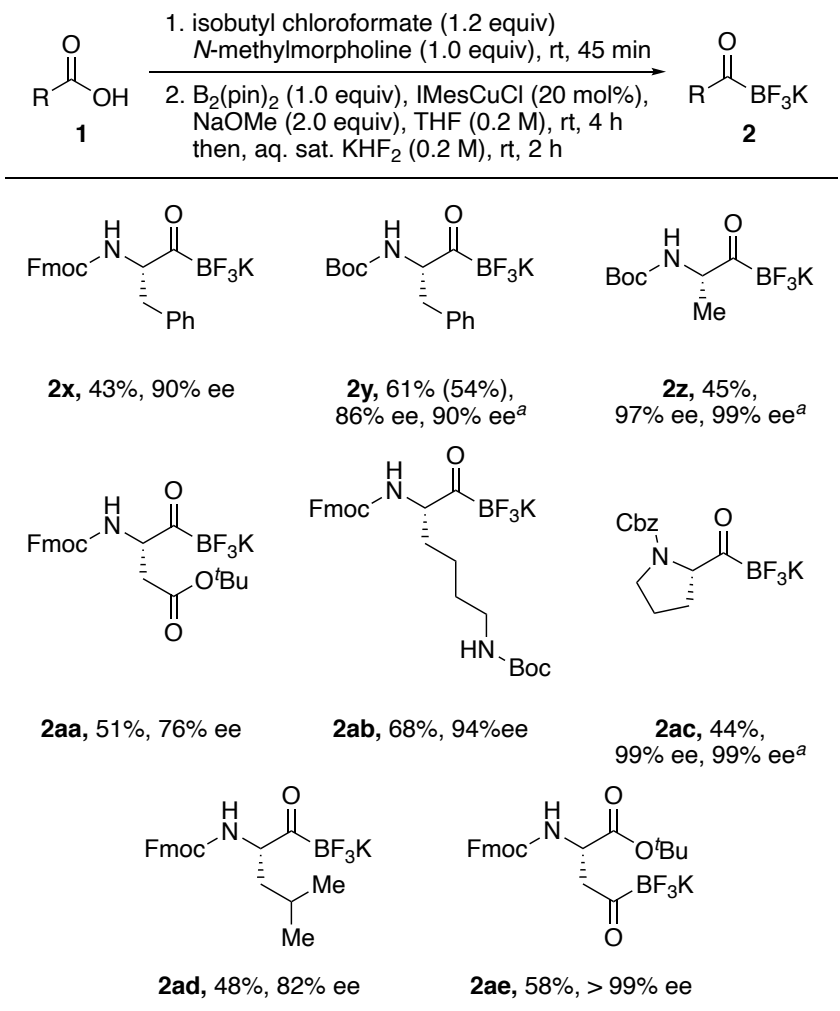

Scheme 2. Substrate scope for the preparation of amino acid-derived KATs. Isolated yields are reported. Reactions were performed on $1 \mathrm{mmol}$ scale. Yields in parenthesis are for reaction performed on a $10 \mathrm{mmol}$ scale. The anhydride is formed using the same conditions as for the other substrates. $\mathrm{B}_{2}(\mathrm{pin})_{2}=$ bis(pinacolato)diboron; $a$ Two ee values are reported for reactions that were repeated and varying ee values were found; $\mathrm{IMesCuCl}=$ Chloro(1,3-dimesitylimidazol-2-ylidene)copper(I); Fmoc = fluorenylmethyloxy-carbonyl; Boc = tert-butoxycarbonyl; Cbz = benzyloxycarbonyl.

We therefore elected to purify the amino acid derived KATs by flash column chromatography, which leads to somewhat diminished yields. While we can readily prepare amino acid-derived KATs with this method, we observe partial racemization, most likely caused by the base present in the reaction. We have confirmed that the racemization does not occur during the anhydride formation by trapping the anhydride with an amine and measuring the enantiopurity. Treatment of an isolated KAT amino acid with $\mathrm{NaOMe}$, however, leads to further epimerization. We therefore postulate that an acylborane or acylboronate intermediate formed during the transformation can epimerize under the basic conditions. This is consistent with the prior observation that the intermediate acylboronate formed during carbonylative coupling of alkyl iodides undergoes facile, in situ enolate formation. ${ }^{8}$ For some KATs $(\mathbf{2 y}, \mathbf{2 z}, \mathbf{2 a c})$, the synthesis was repeated multiple times and somewhat varying ee values were found, suggesting that the reactions conditions play an important role. We are currently attempting to find modified procedures that afford these KATs without epimerization. 
In agreement with our previously proposed mechanism for alkyl iodides, ${ }^{8}$ we propose that the catalyst activates the $\mathrm{B}_{2}$ (pin) $)_{2}$ to generate boryl-copper intermediate $\mathbf{B}$ (Scheme 3 ), which subsequently undergoes oxidative addition with the acid anhydride $\mathbf{A}$ to form $\mathrm{Cu}^{(I I I)}$ intermediate C. Reductive elimination affords acylborane intermediate $\mathbf{D}$, which coordinates sodium methoxide to form of the more stable intermediate E. Catalyst regeneration with $\mathrm{NaOMe}$ likely produces stoichiometric sodium isobutylcarbonate, which may further undergo decarboxylation. Finally, the KAT is formed upon quenching $\mathbf{E}$ with $\mathrm{KHF}_{2}$.

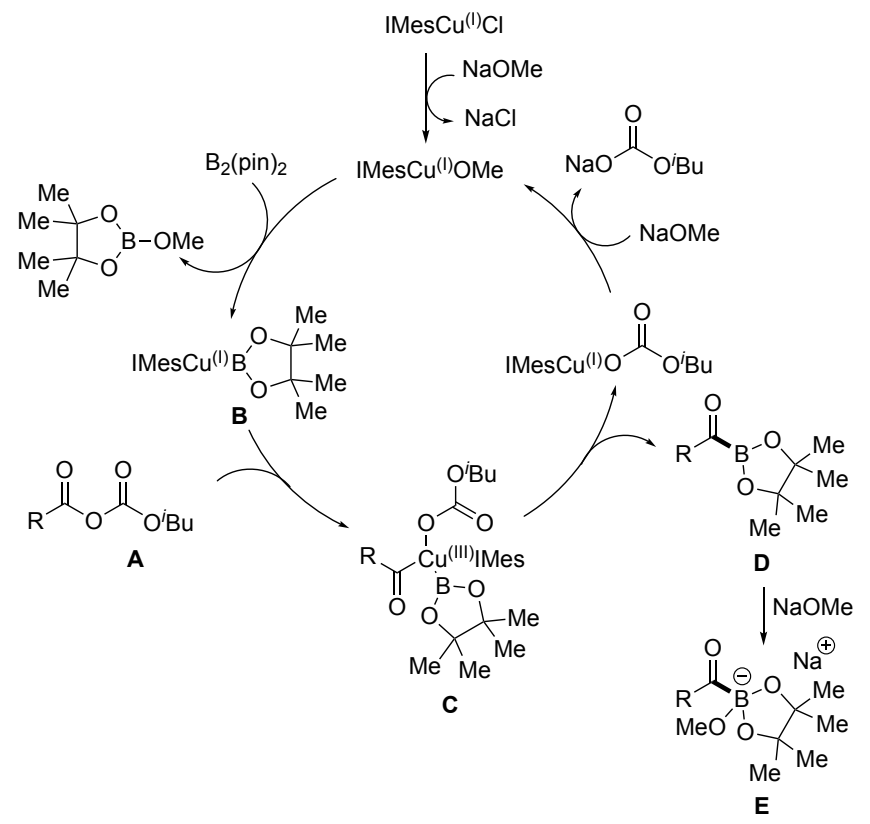

Scheme 3 Proposed mechanism for the transformation of acid anhydrides to KATs, featuring acylboron and acylboronate intermediates $\mathbf{D}$ and $\mathbf{E}$.

In summary, we have developed a method for the preparation of aromatic and aliphatic KATs, including KATs derived from amino acids, from carboxylic acids via their mixed anhydrides. This method complements previously reported methods for KAT synthesis and allows for their straightforward preparation from widely available carboxylic acids requiring only commercial reagents and catalysts.

\section{Acknowledgements}

This research was supported by ETH Zurich and the U.S. Department of Energy (DOE), Office of Science, Office of Basic Energy Sciences (BES), under Award Number DE- 
SC0021055. A. S. acknowledges the Scholarship Fund of the Swiss Chemical Industry (SSCI) for a fellowship. We thank the Molecular and Biomolecular Analytical Services (MoBiAS) and the LOC NMR service at ETH Zurich for analyses. Dr. Li-Jie Cheng (UIC) is thanked for useful discussions.

[1] a) A. M. Dumas, G. A. Molander, J. W. Bode, Angew. Chem. Int. Ed. 2012, 51, 5683-5686; Angew. Chem. 2012, 124, 5781-5784; b) H. Noda, G. Erős, J. W. Bode, J. Am. Chem. Soc. 2014, 136, 5611-5614.

[2] A. Osuna Gálvez, C. P. Schaack, H. Noda, J. W. Bode, J. Am. Chem. Soc. 2017, 139, 1826-1829.

[3] T. Shiro, A. Schuhmacher, M. K. Jackl, J. W. Bode, Chem. Sci. 2018, 9, 51915196.

[4] C. J. White, J. W. Bode, ACS Cent. Sci. 2018, 4, 197-206.

[5] a) G. N. Boross, D. Schauenburg, J. W. Bode, Helv. Chim. Acta 2019, 102, e1800214; b) A. Chiotellis, H. Ahmed, T. Betzel, M. Tanriver, C. J. White, S. Da Ros, R. Schibli, J. W. Bode, S. M. Ametamey, Chem. Commun. 2020, 56, 723-726.

[6] a) D. Mazunin, N. Broguiere, M. Zenobi-Wong, J. W. Bode, ACS Biomater. Sci. Eng. 2015, 1, 456-462; b) D. Mazunin, J. W. Bode, Helv. Chim. Acta 2017, 100, e1600311; c) D. Schauenburg, A. Osuna Gálvez, J. W. Bode, J. Mater. Chem. B 2018, 6, 4775-4782; d) Y. Gu, D. Schauenburg, J. W. Bode, J. A. Johnson, J. Am. Chem. Soc. 2018, 140, 14033-14037; e) D. Schauenburg, M. Divandari, K. Neumann, C. A. Spiegel, T. Hackett, Y. Dzeng, N. D. Spencer, J. W. Bode, Angew. Chem. Int. Ed. 2020, 11, 76097614; Angew. Chem. 2020, 132, 14764-14771.

[7] a) G. Erős, Y. Kushida, J. W. Bode, Angew. Chem. Int. Ed. 2014, 53, 7604-7607; Angew. Chem. 2014, 126, 7734-7737; b) D. Wu, N. A. Fohn J. W. Bode, Angew. Chem. Int. Ed. 2019, 58, 11058-11062; Angew. Chem. 2019, 131, 11174-11178.

[8] L.-J. Cheng, S. Zhao, N. P. Mankad, Angew. Chem. Int. Ed. 2021, 60, 2094-2098; Angew. Chem. 2021, 133, 2122-2126.

[9] S. M. Liu, D. Wu, J. W. Bode, Org. Lett. 2018, 20, 2378-2381.

[10] a) A. M. Dumas, J. W. Bode, Org. Lett. 2012, 14, 2138-2141; b) J. Taguchi, T. Takeuchi, R. Takahashi, F. Masero, H. Ito, Angew. Chem. Int. Ed. 2019, 58, 7299-7303; Angew. Chem. 2019, 131, 7377-7381.

[11] a) A. Schuhmacher, S. J. Ryan, J. W. Bode, Angew. Chem. Int. Ed. 2021, 60, 3918-3922; Angew. Chem. 2021, 133, 3964-3968; b) Z. He, P. Trinchera, S. Adachi, J. D. St. Denis, A. K. Yudin, Angew. Chem. Int. Ed. 2012, 51, 11092-11096; Angew. Chem. 2012, 124, 11254-11258; c) S. Adachi, S. K. Liew, C. F. Lee, A. Lough, Z. He, J. D. St. Denis, G. Poda, A. K. Yudin, Org. Lett. 2015, 17, 5594-5597; d) D. Tan, Y. Cai, Y. Zeng, W. Lv, L. Yang, Q. Li, H. Wang, Angew. Chem. Int. Ed. 2019, 58, 13784-13788; Angew. Chem. 2019, 131, 13922-13926; e) S. Lin, L. Wang, N. Aminoleslami, Y. Lao, C. Yagel, A. Sharma, Chem. Sci. 2019, 10, 4684-4691. 
[12] a) M. L. Lepage, S. Lai, N. Peressin, R. Hadjerci, B. O. Patrick, D. M. Perrin, Angew. Chem. Int. Ed. 2017, 56, 15257-15261; Angew. Chem. 2017, 129, 15459-15463; b) J. Taguchi, T. Ikeda, R. Takahashi, I. Sasaki, Y. Ogasawara, T. Dairi, N. Kato, Y. Yamamoto, J. W. Bode, H. Ito, Angew. Chem. Int. Ed. 2017, 56, 13847-13851; Angew. Chem. 2017, 129, 14035-14039.

[13] a) Y. Segawa, M. Yamashita, K. Nozaki, Science 2006, 314, 113-115; b) J. Campos, S. Aldridge, Angew. Chem. Int. Ed. 2015, 54, 14159-14163; Angew. Chem. 2015, 127, 14365-14369.

[14] H. Noda, J. W. Bode, Org. Biomol. Chem. 2016, 14, 16-20. 